\title{
Les històries franceses de Troia i d'Alexandre a Catalunya i a ultramar
}

Fabio Zinelli

Els lectors d'aquesta revista han pogut llegir un article de Lola Badia sobre la difusió de la matèria troiana a Catalunya (Badia 2007). Concretament es tractava de l'èxit català de la Historia destructionis Troiae, obra del messinenc Guido delle Colonne escrita el 1287, conegudíssima per tot Europa. La Historia va ser traduïda al català entre el $1367 \mathrm{i}$ el 1374 per Jaume Conesa i ha deixat diverses traces en la literatura catalana, des del Curial e Güelfa a Roís de Corella, o al Tirant. Badia recorda, però, que qui va també jugar un paper fonamental en la difusió europea de la llegenda troiana va ser el Roman de Troie, un poema francès de vora 30.000 octosíllabs escrit cap al 1165 per Benoît de SainteMaure, un autor actiu a la cort dels Plantagenet. Al costat de l'obra de Benoît (destacada també a Guido delle Colonne), de la qual queden prop de seixanta manuscrits i que va ser traspassada a la prosa segons cinc versions diferents, la literatura francesa oferia un relat de la guerra de Troia dins d'un altre best-seller, la Histoire ancienne jusqu'à César, una gran obra sobre la història del món, del Gènesi a la història de Roma. Composta el 1213-1214 per a Roger IV de Lille per un autor potser identificable amb Wauchier de Denain (activíssim a la cort de Flandes, a qui devem també textos hagiogràfics i potser una de les continuacions del Perceval de Chrétien de Troyes), va obtenir un gran èxit testimoniat pels setanta-tres manuscrits conservats de l'anomenada 'primera redacció' (la més antiga), molts dels quals estan ricament miniats. Per la part troiana, la Histoire segueix de prop el De excidio Troyae historia, una obra llatina que es remunta al segle $v$ i que es pensava que era la traducció d'un original grec, obra de Dares el Frigi que, segons la tradició, hauria participat personalment al setge de Troia. Els lectors catalans van ser sensibles a l'èxit de totes dues obres i, més en general, al prestigi de la literatura francesa en conjunt. De fet, eren nombrosíssims els manuscrits d'obres franceses, narratives, didàctiques i religioses a les biblioteques catalanes medievals (Cingolani 1990-91). No en sabem gaire, però, d'aquests manuscrits: ni si entre ells hi havia alguns dels còdexs que avui encara conservem, ni si tots havien arribat directament de França, o si alguns s'havien transcrit a Catalunya, tal vegada per obra de copistes catalans. En aquest article ens proposem parlar d'algunes traces concretes de la circulació del Roman de Troie i de la Histoire ancienne en ambients catalans (als dos primers apartats) o en manuscrits que podrien haver estat catalans (als dos darrers apartats). Parlant de la Histoire, el discurs ens portarà lluny de Catalunya per emprendre un viatge pel Mediterrani oriental on trobarem, en un ambient potser català, altres obres franceses de gran èxit: un Roman d'Alexandre en prosa i una de les més cèlebres enciclopèdies de l'Edat Mitjana, el Tresor de Brunetto Latini.

\section{El «Roman de Troie»}

Una prova directa i sorprenent de com n'era de conegut el Roman de Troie a Catalunya es troba dins d'un dels principals documents de difusió de la poesia occitana en aquesta banda del Pirineu: el cançoner trobadoresc Sg (Barcelona, Biblioteca de Catalunya, ms. 146). El cançoner va ser illuminat a Lleida (i, per tant, potser també copiat) a la segona meitat del segle XIV (potser durant el tercer quart del segle, Cabré \& Martí 2010) i s'hi poden llegir alguns del trobadors més importants del període clàssic, seguits d'una an- 


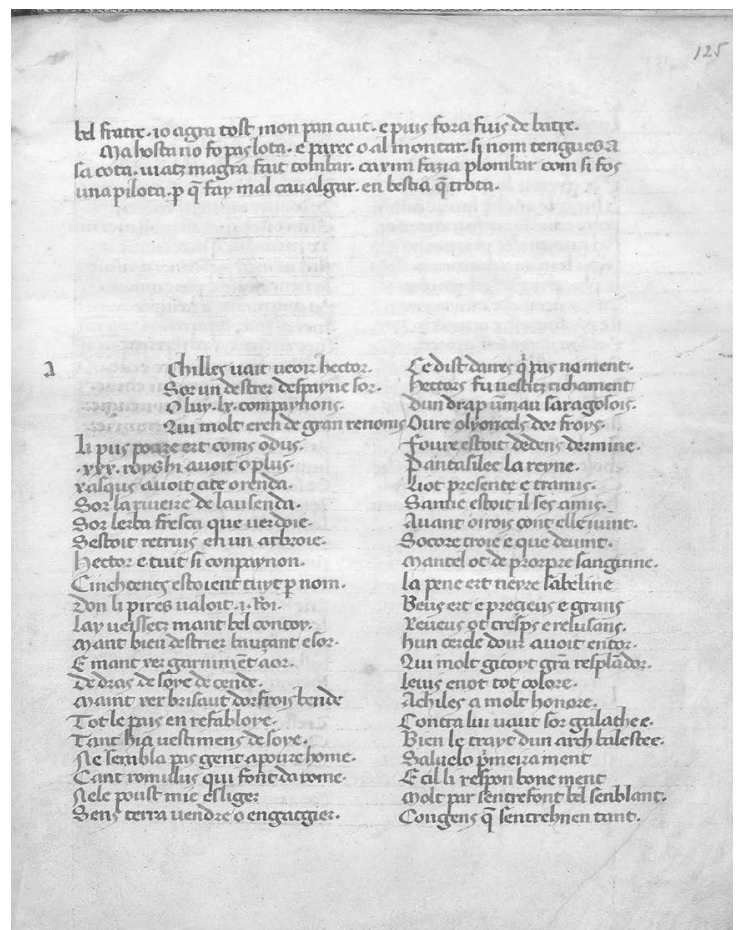

Inici del fragment del Roman de Troie copiat al cançoner Sg (Barcelona, Biblioteca de Cataluya, ms. 146, f. 125r).

tologia de poetes 'contemporanis' del segle XIV que pertanyen principalment a l'escola de Tolosa que, sota la direcció de l'acadèmia del Gai saber, pretenia mantenir viva la tradició de la poesia occitana (Ventura 2006; una visió matisada a Cabré \& Martí 2010). Al final del cançoner el mateix copista hi va transcriure un fragment del Roman de Troie. Es tracta de 248 versos que narren la trobada entre Aquilles i Hèctor, ara enemics mortals després que Hèctor hagi mort Patrocle. La trobada es produeix durant una treva. Hèctor persuadeix Aquilles per resoldre la guerra amb un duel entre ells dos, però aquesta solució serà rebutjada pels caps de tots dos exèrcits. Cadascun dels dos herois elabora un discurs que alhora destaca el seu caràcter: Aquilles, condicionat per la ira i la venjança; Hèctor, més pragmàtic i reflexiu. Aquests versos corresponen a l'anomenada versió llarga del Roman present en diversos manuscrits.' En la intricada tradició del Roman, el text de Sg, editat per Eley (1992), demostra ser

1. Es tracta concretament de 198 versos de la 'redacció llarga' a Constans (1904-12, IV: 399-407), i dels vv. 13207-52, 13257-60 de la 'redacció corrent'. molt pròxim al manuscrit París, BnF, fr. 2181 (sigla K), del segle XIII (Constans 1904-12; Eley 1992). A la transcripció de Sg, el copista hi ha deixat passar diversos catalanismes (Zinelli 2009-10).

\section{Contactes interlingüístics}

Es tracta d'una situació molt freqüent en la còpia de manuscrits medievals, si pensem que els copistes havien sovint d'adaptar el text al dialecte propi o fins i tot, quan es tracta de llengües romàniques, a la llengua a què pertanyien. És, per exemple, el que veiem sovint a les desenes de manuscrits francesos transcrits per copistes italians. També aquí ens les hem amb les interferències pròpies de qualsevol contacte interlingüístic, interferències que són estudiades i analitzades per una branca específica de la lingüística: l'anomenada 'lingüística de contacte'.

Les grafies catalanes són especialment nombroses (i coincideixen en bona part amb aquelles que es troben a la part occitana del cançoner, Zufferey 1987: 248-74). Vegem, per exemple, la conservació de la -a final (terra), la forma -er del sufix francès -ier (destrer), les grafies per $n$ palatal (Espayne, compaynons), c i g palatals (xasqus, xer, xeveus, xose, protxane, engatgier). L'estudi de la llengua, d'altra banda, pot revelar l'existència d'un estadi de la tradició del text que altrament continuaria ignorat. De fet, és possible que un dels manuscrits perduts de la branca de la tradició del Roman utilitzat per Sg (o fins i tot el mateix manuscrit utilitzat com a model pel copista de Sg) vingués del sud de França. Ho podrien demostrar algunes grafies de tipus occità: la grafia nh per a la palatal a compainhie, i, potser, la lliçó del v. 96 «Tart en veirois al repentir», en la qual (si no és un error per venroiz de la majoria dels manuscrits), s'hi pot veure una forma híbrida feta a partir del futur occità veiretz 'veureu'. Un altre indici també pot venir de la morfologia verbal. Es tracta de la forma font per a la tercera persona del perfet del verb ser al v. 22: «Cant Romulus qui font da Rome», on da per de és una grafia que testimonia la neutralització de les a/e àtones en català occidental (Eley 1992 llegeix: fontda; entén potser 'Ròmul que va fundar Roma'?). La forma font correspon a la forma corrent fo, escrita de vegades fon. La - $n$ final és d'origen incert; entre les explicacions proposades, la de veure en -n l'aglutinació 
de l'adverbi pronominal derivat del llatí INDE ajudaria a explicar la presència de la consonant dental en alguns casos occitans d'una forma font. En occità trobem també diversos casos d'una forma fonc, amb l'afegit de la desinència típica dels perfets forts. En català hi ha les mateixes formes fo, fonch, fou, però, pel que jo en sé, només un cas isolat de font al Tirant lo Blanc (trobat gràcies al DTCA). En tot cas, vagi per endavant que no es pot excloure del tot que aquests elements occitans, en Iloc de ser propis del model, hagin estat introduits pel nostre copista que, de fet, acabava de transcriure les poesies occitanes del cançoner i que podia per tant acostar, si no fondre, en un únic horitzó lingüístic l'occità i el francès.

Considerem finalment un possible element de caràcter semàntic que ens torna a portar al vessant del català. Llegim els vv. 187-88: «D'angoixe e d'ire totz trassue | le vis li xant li sancs li mue», en els quals els altres manuscrits llegeixen li vis li teint ('el rostre se li enrojola'). Aquí potser hi podem veure a xant la corrupció d'una forma xaut, equivalent a la tercera persona de cheoir. La forma chaut podria ser un calc del català cau (inf. caure). No oblidem que la tercera persona chaut (a partir d'un infinit chaoir, chaer, vegeu l'Anglo-Norman-Dictionary) es troba en una àrea lingüística molt particular, la dels textos francesos d'Anglaterra, dels qual provenen alguns manuscrits del Roman.)

El sentit global del pas es podria referir a l'expressió corrent tant en català com en castellà, caure la cara ('li ha caigut la cara'), caerse la cara, que indica la somatització sobtada d'una emoció violenta. Si aquesta interpretació és correcta, el model llegia doncs li vis li xaut i això vol dir que el model ja era, al seu torn, obra d'un copista català. És una possibilitat que transformaria en menys aïllada l'empremta d'un èxit català del Roman deixada en aquests versos del cançoner.

Queda per explicar per què el copista va triar precisament aquests versos d'entre totes les aventures i descripcions que ofereix el Roman. Es tracta d'un gust particular del compilador per la retòrica i els bells discursos? De fet, així es poden percebre també moltes poesies dels trobadors. Però potser podem provar de fornir una altra explicació a partir de l'estudi de Miriam Cabré i Sadurní Martí (2010). Els dos autors proposen veure en Pere II, comte d'Urgell i bibliòfil reconegut, el comitent del manuscrit. Sabem, d'altra banda, que entre els seus manuscrits també hi havia un exemplar d'un text francès: la Chanson de geste Godefroi de Bouillon també anomenada Chevalier au cygne (Cingolani 1990-91: 69-70). Per tant, no és impossible que el còdex usat per a la còpia del fragment del Roman a Sg fos un manuscrit ja en possessió de Pere II o fins i tot copiat per a ell. ${ }^{2}$ Pere II era fill i successor de Jaume II, comte d'Urgell, mort el 1347. Del 1345 al 1347, l'any de la seva inesperada mort, Jaume II s'havia trobat enfrontat al seu germà, Pere III, rei d'Aragó en un aspre conflicte, la revolta de les Uniones. La noblesa aragonesa i la valenciana s'havien alçat en armes després de la palesa violació per part de Pere dels drets de successió al tron en cas de mort del sobirà segons els quals, si no hi havia hereus mascles, la successió pertocava al germà de més edat del rei. Pere havia negat aquest dret a Jaume en favor de la seva pròpia filla, Constança. Precisament una poesia continguda a la part de Sg dedicada als poetes 'moderns', el vers Trop me desplay can vey falir de l'aragonès Tomás Peris de Foces, alludiria a la solució del conflicte durant els últims mesos del 1347 (Cabré, Martí \& Navàs 2010; Cabré \& Martí 2010). Podríem doncs preguntar-nos si la trobada entre els enemics mortals Hèctor i Aquilles es pot considerar un ressò de la lluita que va enfrontar els dos germans rivals, i que gairebé servís, recordant la guerra que havia decidit la sort del món antic, per declarar la voluntat del nou comte d'Urgell de mantenir-se en posició de pau.

\section{Dos testimonis de la «Histoire ancienne jusqu’à Césarı}

El següent cas és particularment complex i té a veure amb dos dels manuscrits més cèlebres

2 Cabré \& Martí (2010: 134), sostenen la hipòtesi que les seccions de poesia occitana reconeixibles a $\mathrm{Sg}$ serien una còpia de reculls ja en possessió de Jaume II. 
de la Histoire ancienne jusqu'à César. Comencem amb el còdex París, BnF, fr. 20125, ricament miniat i triat com a manuscrit base de tots els que han publicat parts d'aquesta llarga compilació d'història bíblica i profana. ${ }^{3}$ Del lloc on es va elaborar el còdex, se n'han formulat diverses hipòtesis. Per les seves quaranta-nou miniatures (però també per la versió del text de la Histoire que contenen), el cicle illustratiu del còdex és molt proper al de tres manuscrits copiats segurament a la segona meitat del segle XIII a Terra Santa, a Acre, abans que la ciutat caigués en mans musulmanes el 1291. Es tracta dels manuscrits Brusselles, Bibliothèque Royale, 10175; Dijon, Bibliothèque Municipale, 562 (el més antic; hi tornarem al final d'aquest apartat); i Londres, Brithis Library, Add. 15268 (Buchthal 1957: 68-87; Oltrogge 1989: 54-61). A prop se situa també BnF, fr. 9268, copiat a França (segons els historiadors de l'art acabats d'esmentar) però la llengua del qual revela la presència de moltíssims trets del francès d'ultramar (Zinelli 2012; Nobel 2012), tant és així que si més no el seu model s'ha de localitzar a ultramar. Recordem que en els últims anys ha crescut l'interès dels estudiosos pel francès parlat als estats croats (Minervini 2010). Llengua de comunicació entre persones d'orígens i cultures molt diverses, aquesta mena de francès tolera naturalment un grau elevat de contaminació. El lèxic porta traces d'italianismes (venecians, genovesos i pisans asseguraven el pas per mar dels croats) i, naturalment, nombrosos préstecs de l'àrab. L'occità i els dialectes occidentals del francès hi han jugat igualment un paper important.

N'hi haurà prou amb recordar formes com leuc, feuc, jeuc (per lieu, feu, jeu), amermer (occ. amermar 'disminuir', del llatí MINIMUS). És una situació que reflecteix el fet que el comtat de Trípoli hagués estat el centre de la zona d'influència dels comtes de Tolosa i que la família pitavina

3. Visser van Terwisga (1995), Assiri, Tebe; Jung (1996: 358-430), Troia; Joslin (1986), Genesi; Gaullier-Bougassas (2012), Alessandro. dels Lusignan jugués un paper de primer ordre a Terra Santa i a Xipre.

Pel que fa al manuscrit BnF fr. 20125, també se n'ha proposat un origen a Terra Santa. En particular es tractaria de l'obra d'un deixeble d'un miniaturista, parisenc de formació però en actiu a Acre, rebatejat als estudis amb el nom de Maître de l'Hospitalier, a la mà del qual serien atribuïbles diversos manuscrits (Folda 1976: 95-102; 2005: 429-33). ${ }^{4}$ Les conclusions de Jaroslav Folda, que creu poder datar el manuscrit vora el 1287, han estat acceptades majoritàriament, amb l'excepció de Doris Oltrogge, que en un libre específic sobre els manuscrits de la Histoire pensa en canvi que el manuscrit es va realitzar a París o al nord de França durant el tercer quart del segle XIII. ${ }^{5}$

No en sabem gairebé res de la història del manuscrit. L'únic element útil és la presència als marges d'algunes anotacions que tenen per finalitat ajudar el lector a retrobar ràpidament alguns passatges resu-

\section{Resseguint l'origen del manuscrit}

Doris Oltrogge s'atreveix fins i tot a posar en dubte l'existència mateixa de l'atelier del Maître de l'Hospitalier (1989: 302-07). Un problema particular per resoldre ve representat pel dialecte francès usat pel copista. Per això hem de recordar que França es presenta a l'Edat Mitjana dividida lingüísticament en zones dialectals sobre les quals París encara no té una posició dominant. És segur que la llengua del còdex presenta un cert nombre de trets propis del nord de França i de la Picardia (Visser van Terwisga 1995; Gaullier-Bougassas 2012), encara que, va bé precisar-ho, alguns trets fonamentals del dialecte picard hi estan poc representats (la no palatalització de ca-: caure, forma freqüent per chaure 'calor'; catoner 'chatonner' f. 91vb), o

4. Derbes \& Sandona (2004) pensen que BnF fr. 20125 ve d'ultramar pel relleu atorgat per les seves miniatures (igual que el que trobem en els tres manuscrits d'Acre) a la història de les amazones.

5. Així també Buchthal (1957: 70), que esmenta el manuscrit però només de passada. 


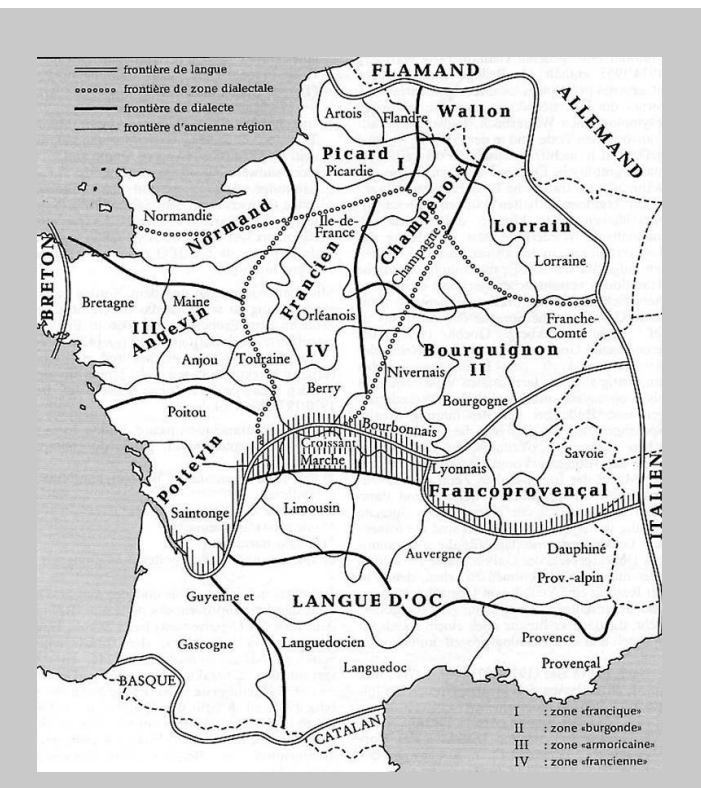

són absents (el pas de ce, ci a che, chi, com seria, per exemple, als pronoms chist, chest) i que dels restants elements picards alguns tenen un difusió geogràfica encara més àmplia (per exemple, l'article femení le, els plurals en -iaus).

Visser van Terwisga (1995), aplicant un mètode d'anàlisi estadística d'un nombre massa limitat de variants, es decanta per un origen a la Xampanya (al departament de l'Haute-Marne), fins i tot reconeixent la presència d'elements del nord-oest (Lille), possibles restes de la llengua de l'original (fet, ho recordem, per a Roger de Lille), però també de l'est (Verdun). Si tornem, però, a la hipòtesi de Folda segons la qual el còdex hauria estat copiat a Acre, ens hem de demanar si la llengua del còdex presenta trets típics del francès d'ultramar.

Observem de seguida que hi falten les formes més típiques (els citats leuc, feuc, ziaus 'ulls', el passatge de s preconsonàntica a $h$, per exemple ihle per isle), i que té sempre el francès amenuisier en Iloc d'amermer. Hi trobem en tot cas trets propis dels dialectes de l'oest de França presents també en la llengua d'ultramar: sobretot la freqüència de l'absència d'evolució del diftong ei en oi (creire, freidure, aveit etc.), i formes com mau ('mal', amb velarització de la -l final), segur (per 'seür', 'sûr'). També alguns caràcters aparentment picards són freqüents a ultramar: recordem el substantiu aigue (en aquest context concret es pensa en l'influx de l'occità agua). N'hi ha prou de recórrer les parts de text ja editades per trobar-ne d'altres: el manteniment de la - a final a corona (porta corona f. 84d, hi podria ser, simplement, per influencia de - $a$ final del perfecte porta), el consonantisme occità de tible ('tegola' f. 13va; cal dir que els altres manuscrits del grup llegeixen també tible, vegeu Pignatelli \& Gerner 2006: 91), la freqüència de la grafia $z$ per s intervocàlica (choze, oziaus). [Una dissertació lingüística més sistemàtica és en premsa a l'edició de la part de la Histoire consagrada a la història dels perses, a cura d'Anne Rochebouet (per a la collecció on ha estat publicat Gaullier-Bougassas 2012), que ha estat tan amable de comunicar-me les seves conclusions.]

Val la pena parar atenció a la presència d'un tret tant italià com occità com és l'ús de la preposició articulada per al complement de matèria a chapeau dou fer (f. 116b). Rar, però tot i així present en francès antic (vegeu alguns dels exemples recollits a TL, 270-71, 1219), aquest tret no és present en els altres manuscrits del grup que tenen de fer, sense l'article i, per tant, s'ha de considerar com introduït pel copista o com una lliçó ja del mestre del grup banalitzada després per la majoria de testimonis. Hem de concloure per això que, encara que siguin absents molts dels trets més marcats del francès d'ultramar, el manuscrit va ser copiat a Acre? De fet, podem recordar que també un còdex segurament copiat a Acre, com és l'esplèndida Bíblia de l'Arsenal (París, Bibl. de l'Arsenal, 5211) realitzada per a Lluís IX, no presenta trets lingüístics massa marcats (Nobel 2003: 51; Nobel 2006: XXVII). O bé, els trets lingüístics realçats s'han de considerar perquè es mantenen d'un model d'ultramar mentre, com vol Oltrogge, el còdex va ser copiat a França?

mint-ne el contingut. Estan escrites per una mà que crec que encara és del segle XIII (parla de la «fi de l'Edat Mitjana» Gaullier-Bougassas 2012: 44) en una llengua ja definida «provençal/català» (Visser van Terwisga 1999: 25, 66-67). ${ }^{6}$ Un examen atent revela que la llengua d'aquestes anotacions és el català. Llegim al f. 84rb: «que Ninus fo

\footnotetext{
6. Joslin (1986: 24): «Marginal comments by someone of Spanish origin».
} 
lo primer rey d'Asire e regna sobre tots aquests reys»). Si el perfet fo pot ser tant català com occità, és només català el perfet - a regna que trobem també al f. 8zva porta i al f. 16va «com mudare(n) lo nom». El sufix -er a primer (també als f. zvb, 7ra, 19rb, 8zva i hobrer al f. 7ra), és típicament català (en occità és minoritari respecte de -ier, -ieir, -eir). Això mateix val per la grafia -ts (rara en occità). Continuant la lectura de les glosses, remarquem que són tant catalans com occitans l'article lo (també a 16va, 83va, los a 13vb, 17vb, 18va), la grafia gatge (f. zvb); la caiguda de la -n a fundacio (de fundacio de Atene, f. 85 rb); i els substantius ciutat (f. 7ra, 95rb), fere 'ferro' (f. 7ra), ila 'illa' (f. 16vb), la preposició articulada dels (f. 7ra dels primers horguens, 18va dels Aremjniens). Són catalans el plural armes («lo primer que porta armes» f. 83va), i potser la forma da per a la preposició de (f. 95rb «da Adrastus rey e de la ciutat d'Arge»), amb una grafia consegüent a la neutralització d'ale àtones, però també es podria tractar d'un error d'anticipació de la a del nom següent. Així doncs, les postilles són en català. En canvi crec que és dificilíssim comprovar que el copista del còdex fos català a partir, a banda dels esmentats casos de - $a$ final (que no son gaire rars al francès d'ultramar), d'indicis com la grafia ch a sech al f. $107 \mathrm{vb}$, que pot semblar catalana però es troba de vegades també en copistes francesos i (amb totes les limitacions expressades a dalt) el sintagma citat chapeau dou fer, del qual es troben exemples també en el català rossellonès de les Vides de sants. La hipòtesi més probable és que el còdex, fos on fos que va ser copiat, arribés ja al segle XIV a Catalunya. En l'estudi citat de Cingolani (199091: 96-98), trobem traces a les biblioteques catalanes del segle $x v$ d'almenys tres compilacions d'història universal que podrien correspondre a tres manuscrits de la Histoire (complets o parcials): les Istories thebanes et troyanes en possessió de Carles d'Aragó, príncep de Viana; el llibre part de Històries Troyanes e part de Alexandre venut a Ramon Vales per Guillem Garriga (1461); i el Genesi e lo troye (1466) de Francesch de Camelles.

En tot cas, una altra hipòtesi és possible si el còdex va ser copiat realment a Acre: que les anotacions catalanes fossin escrites una mica més tard en algun $\|$ oc del Mediterrani on podien haver-hi catalans, ja sigui a Xipre, a Rodes o a Grècia. Arribem així a l'última part del nostre viatge en el qual aquesta possibilitat, que queda del tot hipotètica pel que fa a BnF fr. 20125, pren cos respecte d'uns quants altres testimonis.

Entre els llibres documentats en biblioteques catalanes que sabem que contenien només matèria troiana, hi havia les Istories Troyanes de Martíl (1410) en francès i, probablement també, l'obra del mateix títol en possessió de na Tomasa sogra d'Albert de Montergull (1422).

La possibilitat que la llegenda troiana es llegís en cercles catalans esdevé molt concreta si tornem a considerar el ja esmentat còdex de Dijon, Bibliothèque Municipale, 562, que va ser copiat, aquest sí, a Acre. Tampoc no sabem quasi res de la història d'aquest manuscrit (al f. 274V trobem una nota de possessió del segle XIV on surt un nom italià: el d'un desconegut Pietro de Nola). Als marges del manuscrit hi ha moltes anotacions, potser encara del segle XIII o del segle XIV.7 Si mirem bé, ens adonem que aquestes també son en català.

Podem citar els perfets poblaren f. 107r, apellar(en) f. 107v, fundaren f. 129r, ordonà 133r, foren f. (f. $250 \mathrm{~V}$ «açi foren desconfits los romans»); f. $251 \mathrm{~V}$ «açi foren desconfits los galoys per los romans»), féu 107r; les grafies amb y per $n$ palatal: compays f. 109v, 110v, seyor f. 231v, Espaya 262r

Podria tractar-se certament d'una coincidència: dos manuscrits de l'Histoire ancienne que pertanyen a una mateixa família textual i amb força semblances en les miniatures que haguessin anat a parar independentment en mans catalanes. Però es podria pensar també que la coincidència no fos gaire fortuïta. Caldria pensar, en aquest cas, que, com vol Folda, BnF fr. 20125 havia estat copiat a Acre, igual com el còdex de Dijon. Després de la caiguda de la ciutat, els dos manuscrits haurien estat comprats per catalans, que els haurien conservat uns quants anys. La

7. Oltrogge (1989:246): «mehrfach Randnotizen des 13.Jh». 
hipòtesi pren cos si pensem en altres casos de manuscrits d'Acre que, quan els seus propietaris havien fugit a Xipre o a Grècia, s'havien quedat inicialment al Mediterrani oriental, això mateix hauria pogut passar també a l'orient.

\section{Les biblioteques dels catalans a ultramar}

La presència catalana a orient és un argument tant important com estudiat. No hi ha espai per citar ni tan sols sumàriament la rica literatura històrica sobre aquest argument (per exemple, Ferrer i Mallol 2000). Per fer-se'n només una idea, n'hi ha prou d'agafar un monument com la collecció de documents a cura de Rubió i Lluch (1947). També pel que fa a l'imaginari literari, l'orient mediterrani és un fons geogràfic ben present a la literatura catalana, com palesa la història de Jacob Xalabín, en el Curial o en el Tirant. ${ }^{8}$ Diversos llibres deuen haver circulat certament per mans catalanes al Mediterrani oriental, potser també hi hauran estat copiats. Volem considerar aquí la hipòtesi que entre aquests volums que devien circular, dels quals avui no sabem gairebé res, s'hi podrien trobar també alguns manuscrits del Tresor. El Tresor és una divulgadíssima obra enciclopèdica en tres llibres (sobre el món celestial i natural; sobre l'ètica; sobre la retòrica i sobre el seu ús polític) escrita en francès pel florentí Brunetto Latini després del 1260, a l'època del seu exili a França. L'obra, conservada en almenys noranta manuscrits, es va traduir a moltes llengües. N'hi ha també dues traduccions en català, una d'elles anònima, l'altra obra de Guillem de Copons, que va traduir l'obra al voltant del 1418 (Wittlin 197189). D'entre els manuscrits del Tresor podem identificar una família que deriva molt probablement d'un model d'ultramar. Tots els testimonis més antics d'aquesta família presenten els trets

8. Ara s'hi pot afegir probablement també el Cardenois, novella francesa d'aventures cavalleresques de final del XIV (en bona part es desenvolupen en un regne mediterrani no més precís) que contenen diversos elements que sembla que el relacionen amb Catalunya (cf. Alberni 2012, Lagomarsini 2012, Zinelli 2012a).

9. Per a la presència de manuscrits del Tresor francès a la Catalunya medieval, cf. Wittlin (1971: 16-17). lingüístics típics del francès d'ultramar (Zinelli 2007). El més antic, potser encara del segle XIII, Torí, Biblioteca Nazionale Universitaria, 1643 (abans L. II. 18), greument malmès per l'incendi del 1904, presenta miniatures d'un estil que sembla pròxim al del Maître de l'Hospitalier (Roux 2009: 89). L'origen ultramarí ve confirmat per una nota de possessió antiga en caràcters grecs refe-

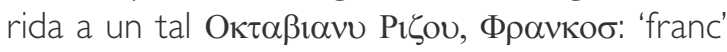
era el nom que en l'ús d'ultramar designava un individu d'origen 'occidental'. Al foli de guarda final s'hi poden llegir tres poesies escrites per una mà del principi del segle XIV: dues són en italià. La tercera és la cançó occitana anònima BdT 461,18a Amors m'a fach novelamen asire, que s'ha cregut obra d'un autor català (Gambino 2003: 137-43), però això no és segur.10

Pertanyen a la mateixa família de còdexs tres manuscrits probablement copiats en un mateix scriptorium: Londres, British Library, Add. 30024 i Add. 30025; i Carpentràs, Bibliothèque Inguimbertine, 269." Ho demostra la similitud en la decoració en ploma (filigranada) de les lletres inicials de capítol i en les miniatures dels còdexs. Una característica comuna important té a veure amb el retrat d'Aristòtil al principi del llibre II del Tresor dedicat a una traducció de l'Etica Nicomachea. Aristòtil apareix als tres manuscrits representat com un savi oriental amb el cap cobert amb un turbant. Al manuscrit de Londres, Add. 30025 apareix assegut a la oriental i llegeix un pergamí en caràcters pseudoàrabs (f. 73v). És especialment interessant recordar aquí que en el manuscrit de Carpentràs hi trobem diverses anotacions, escrites per diverses mans, concebudes com un ajut a la lectura del text. La major part, per una mà contemporània a la del còdex, i en una llengua que sembla una barreja de francès (és

10. Zinelli (2007:47, n.168). Els vincles intertextuals destacats amb les poesies de Cerverí de Girona es podrien explicar a través de les composicions d'un altre trobador cèlebre com Bernart de Ventadorn. Les grafies amb $x$ intervocàlica al text de la cançó (plaxenz, dexir, raxon, playxenz) semblen més de tipus venecià que català.

11. Zinelli (2007:48-52). Roux (2009:90-94) pensa en canvi en una localització tolosana partint de la base de semblances, que per a mi són genèriques, amb la bíblia hebraica de Perpinyà (París, BnF, hébreu 7). 
a dir, paraules franceses agafades directament del text del Tresor) i d'occità (plurals femenins en -as, za. persona del plural de l'indicatiu amonestan, i vegeu la grafia occitana li $<n>$ hatge al f. 12ra). En canvi, es podria pensar que és català el fons lingüístic de la nota al f. 112ra (de mà contemporània a la precedent): «Aissi a que virtuts non avem per natura mais per doctrina, pero le comenssamens naturals es en nos que aprenem vertuts». Considerem de fet la grafia -ts en posició final, molt més rara en occità (que fa servir -tz). La forma de l'article le, però, és occitana i en particular tolosana (no és desconeguda en el català medieval, on es limita però a la llengua de la poesia i per tant s'ha de considerar un occitanisme), però també es podria tractar d'un ressò de l'èxit francès.

D'altra banda, al primer dels dos manuscrits de Londres, hi trobem una miniatura que representa l'Arbre dels vicis i de les virtuts, que recorda molt les representacions de l'Arbre d'amor als manuscrits llenguadocians i catalans del Breviari d'amor de Matfre Ermengaut, obra del final del segle XIII on l'autor elabora una visió cristiana de l'amor i de to crític amb la poesia dels trobadors. Finalment, una mà que sembla contemporània a la del copista ha afegit al f. 109rb una estranya traducció interlineal: «et fait euvre [en obre]», «eslisent meaus [elegen mes]», que pot fer pensar en el català (a través de la desinència -en i si mes

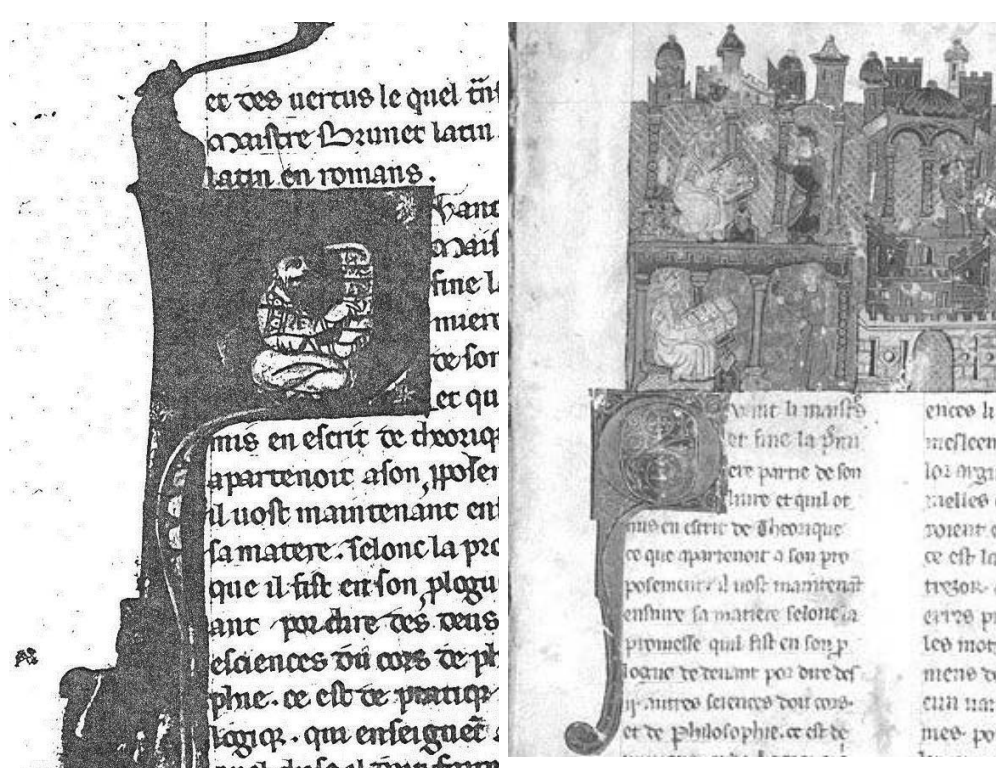

Els manuscrits del Tresor de Londres (es) i Carpentràs (dr) presenten una gran semblança en la decoració. és l'adverbi més; la mateixa mà escriu al f. 109va la traducció: «chaesté ['abstinença']» que pot ser tant catalana com occitana).

\section{Un «Roman d’Alexandre» català?}

Hi ha encara un altre manuscrit les miniatures del qual es revelen molt pròximes a les d'aquests còdexs, i més concretament a les del còdex de Carpentràs. Es tracta del còdex V.u.2o de la Biblioteca Reial d'Estocolm, del segle XIV, que conté una versió del Roman d'Alexandre en prosa, que és una traducció de la Historia de Preliis llatina, el text que més ha comptat en la difusió de la llegenda d'un dels grans herois de l'antiguitat (Meyer 1886, 2: 305-13; Hilka 1920; Cary 1956: 46-48). Al manuscrit d'Estocolm, el Roman està farcit d'interpolacions d'altres obres. De fet s'han inserits dins les històries d'Alexandre dos llargs fragments d'una traducció del Secret des Secrets (present en quatre testimonis més, vegeu Monfrin 1982: 83-85; Zamuner 2005a: 53). El Secret des Secrets és un tractat en forma de carta que, segons la tradició, Aristòtil hauria enviat en qualitat de preceptor al seu propi deixeble Alexandre el Magne. Es tracta, però, d'una ficció. L'original és un text àrab del segle $x$ traduiit al llatí i després a gairebé totes les llengües de l'occident medieval. Se'n coneixen també algunes versions en català (Zamuner 2005a: 66-75, Zamuner 2005b; Cifuentes 2006: 174-76). Al manuscrit d'Estocolm, a banda del Secret, s'hi ha inserit a la història d'Alexandre dos passatges del Tresor (els capítols del bestiari de peixos, i la part de la geografia d'Europa) segons un text que presenta moltes semblances amb el text dels testimonis considerats fins ara (Zinelli 2007: 67-69). Pel que fa a la decoració, tornem a trobar fons exòtics a les miniatures del manuscrit i, sobretot, torna a aparèixer el personatge d'Aristòtil amb el turbant', assegut a l'oriental, en l'acte d'escriure en un pergamí amb caràcters 
pseudoàrabs: al f. 5V, on es tracta del mag Nectanebus; Aristòtil mateix, al principi de la interpolació del Secret des Secrets (f. 37r); el mateix, al costat de la roda de la fortuna (f. 78r). Molt gran, a banda de la figura d'Aristòtil, és també la semblança de les inicials filigranades amb les dels còdexs del Tresor de què parlàvem. El tipus lingüístic del manuscrit correspon al del francès d'ultramar. Hi trobem les formes feuc i leuc, mehlé, els substantius amermance (evolució occitana a partir de MINIMUS), zeaus ('ulls', f. 7ra, 15ra), fiege ('fetge'), els dos italianismes velles i nave (per voiles i nef, cf. Minervini 2000: glossari), tots dos dins de la primera interpolació del Tresor (f. 67va-68rb).12 Tinguem en compte també el complement de matèria (ja destacat al segon apartat): la cage del fer (f. gra).

El manuscrit s'havia considerat d'origen espanyol o portuguès, partint d'una mala lectura d'algunes inscripcions encara del segle XIII presents al verso de l'últim foli (Söderhjelm 1917: 308). Aquestes, de dues mans diferents, són però en català. S'hi pot llegir una sèrie de deutes que ens ofereixen indicacions precioses sobre persones i propietats referides a la província de Lleida («madona Saurina d'Uluya» és a dir Oluges, «Romeu d'Aguilar mercader», «lsarn de Melió») i a les no llunyanes Manresa (província de Barcelona) i Queralt (província de Tarragona, si es tracta de Santa Coloma de Queralt, o bé de la provincia de Barcelona, si es tracta de la serra de Queralt).13 No és impossible que el copista del còdex fos català. Hi trobem, de fet, algunes formes que podrien recolzar aquesta hipòtesi:14 cutious 'acuitat' («je non sui si cutious en vos besoignes con je devroie»); secude («La racine de ceste herbe pistee et poudree en emplastre secude les plaies et les garist»), de secudir, 'espolsar, prémer', aquí però probablement 'buidar, fer supurar'; se fastigeront («Car puis que les oreilles des oians seront saulees de ces paroles, les corages ensement se

12. Bona part d'aquestes formes es troben en un altre testimoni del Roman datable al segle XIV (París, BnF, fr. 1385) a tenir en compte en tant que copiat a ultramar (era italià per a Meyer 1886, 2: 306).

13. No vaig poder llegir aquests noms a Zinelli (2007), perquè aleshores disposava d'una fotografia de mala qualitat.

14. Als fragments publicats a Söderhjelm (1917: 320, 322, 332).

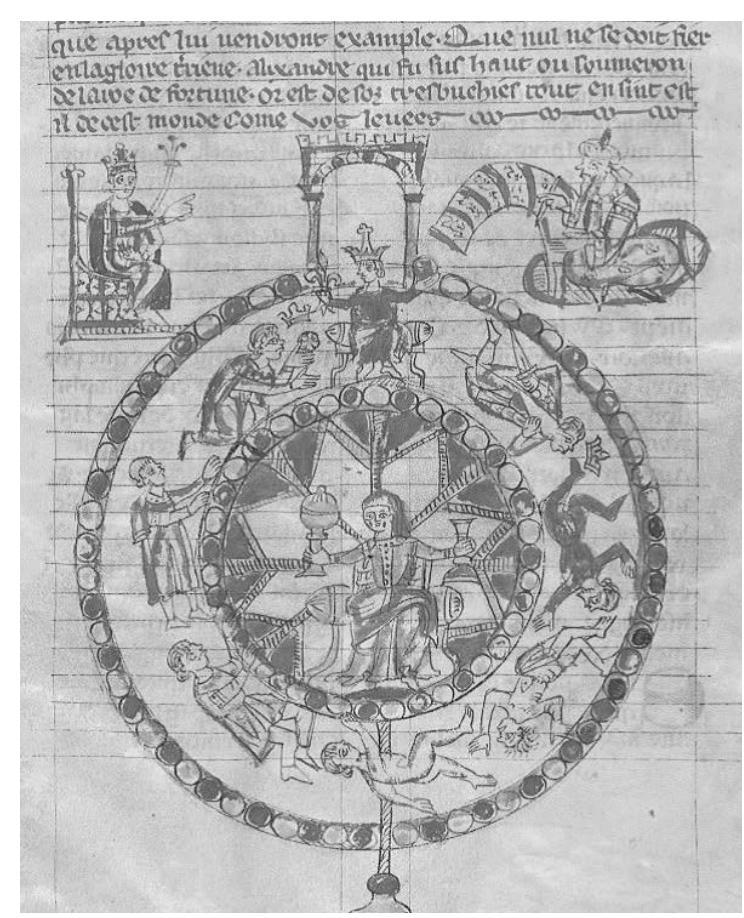

Aristòtil representat a l'oriental sobre la roda de la Fortuna (Estocolm, Kungliga Biblioteket, ms. V.u.20).

fastigeront et ne vouront gaires volentiers veoir ne oir sa parole»). ${ }^{15}$ En tot cas, val a dir que són formes que tenen correspondència en occità (cochos i coitos, socodre, fastigar). ${ }^{16}$ A més poden ser reflexos atribuïbles a un copista tant català com occità: receure ('recevoir'), el pronom tònic te («tu as te doné» f. 6rb, «solieve te» f. 6va). En canvi, sembla més occità l'adverbi deis (f. 1r, gra 'des de'): però totes aquestes formes poden entrar igualment a la mitjana lingüística 'híbrida' del francès d'ultramar.

Si la posició dels tres còdexs del Tresor en la tradició de l'obra i els fets lingüístics que aquests tenen en comú amb l'Alexandre porten a plantejar la hipòtesi d'un origen en un scriptorium per localitzar al Mediterrani oriental, les notes mar-

15. DECLC: II, 1096, cuytos 'precipitat'; DECLC: VII, 568; secodir (sUCCUTERE), «en sentit veí del d'espolsar», amb un exemple d'un document barceloní del segle XIV: «que I comprador pusca secudir de la carn la sal qui s'i tenga, ans del pes»; DECLC: III, 908, s.v. fastic; la forma corrent del verb és fastiguejar, la forma no sufixada fastigar ve testimoniada per les glosses catalanes de Munic (vora el 1400).

16. Per socodre, secodre, vegeu FEW: XII, 384; SW: VII, 735. Per la forma occitana fasticar, vegeu FEW: III, 430b; SW: III, 418. 
cades al foli de guarda, referides a llocs i a persones de Catalunya, sembla aportar més aviat una indicació de la història successiva del còdex (però vist tot plegat, ni tan sols això és segur: el document podria formar part de l'arxiu privat d'un català que es trobava lluny de casa seva). Queda oberta la possibilitat de determinar amb més precisió l'origen del copista. Sobre el fet que el Roman d'Alexandre fos conegut a ultramar podem ara proporcionar un indici més. De fet, el text sembla ser citat per un dels autors més importants i en actiu als regnes cristians d'orient, el cavaller i jurista d'origen italià Filippo da Novara (ca1195-ca1265), que va passar bona part de la vida a Xipre i a Beirut al servei de la família dels Ibelins. Entre les seves obres hi trobem un interessant tractat pedagògic titulat Les quatre âges de l'homme. L'obra conté diverses cites literàries, explícites o dissimulades, com seria el cas del diàleg entre Alexandre i el seu pare, Felip de Macedònia. Mentre Felip apareix excepcionalment com a violent i avar ( $\$ 67$ «crueus et orguilleus et eschars»), Alexandre representa el tipus del senyor feudal generós («preuz et hardiz et larges seur touz homes»), un tipus difós per tanta literatura medieval que esdevé quasi proverbial. Ara bé, el diàleg sembla construït fent servir fragments i idees del Roman d'Alexandre (Schulze-Busacker 2009: 139-41). De fet, la caracterit- zació de Felip és igual que la del Roman: «En celui tens avoit en Macedone .i. roi preu et hardi, mais mout estoit escars et cruels» (Hilka 1920: 19-20), on Alexandre, un cop més, apareix com el model del bon príncep («estoit raemplis de toutes bonnes teches que princes doit avoir en luì»).

Recordem que, de fet, és aquesta la imatge difosa d'Alexandre, tant que podem recordar el destacabilíssim exemple de Pere d'Aragó, definit per Desclot al pròleg de la seva Crònica com un nou Alexandre: «lo rei En Pere d'Aragó, qui fou lo segon Alexandri per cavalleria e per conquesta» (Cingolani 2010: 55; i vegeu Cingolani 2006a: 193-97; 2006b: 309-12). De traces de les històries d'Alexandre a Catalunya se'n troben per altra banda gràcies al record dels llibres passats per mans catalanes a l'Edat Mitjana. Entre ells (Cingolani 1990-91: 96-98, n. 197 i 194), un Alexandre en francés és a les mans de Don Pedro de Portugal el 1466 i, probablement, donada la natura 'francòfila' de la seva biblioteca, també era francès l'Alexandre de na Tomasa, sogra d'Albert de Montergull (1442, vegeu el requadre a la p. 12). La còpia del manuscrit d'Estocolm representaria, en resum, un exemple més de l'èxit català del Roman, però aquesta vegada potser a ultramar i segons una ruta encara del tot per explorar.

Traducció de MARIA ZaRAGOZA
Fragment d'una miniatura de la Historia Destructionis Troiae, de Guido delle Colonne (Cologny, Fondation Martin Bodmer, ms. 78, f. 39r, Venècia (1375).

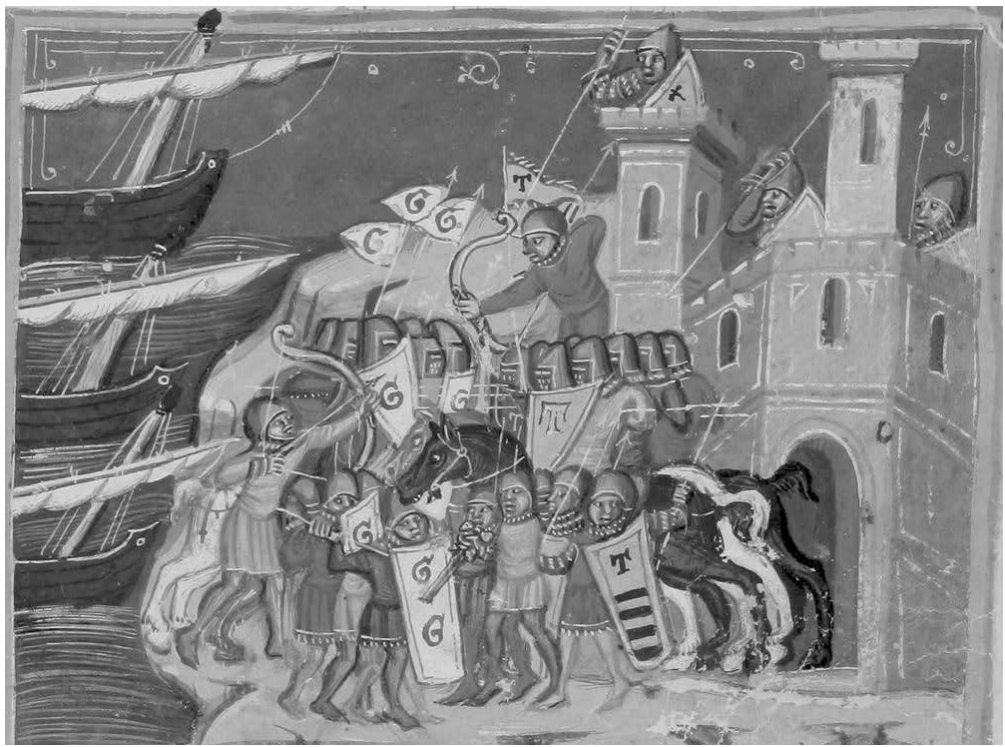




\section{Bibliografia citada}

AlbernI, Anna, 2012: «El Roman de Cardenois i l'emprenta de Guillaume de Machaut en la poesia catalana medieval», Romania, 130, 74-108.

Anglo-Norman Dictionary, ed. Louise W. StONe et William RothWELL, Londres: The Modern Humanities Research Association, 1977-92, 7 vols.

BADIA, Lola, 2007: «La guerra de Troia i les lletres catalanes medievals (segles XIII-XV)», Mot so razo, 6, 32-46.

Buchthal, Hugo, 1957: Miniature Painting in the Latin Kingdom of Jerusalem, Oxford: Clarendon Press.

DECLC = Joan COROMINES, Diccionari Etimòlogic i Complementari de la Llengua Catalana, Barcelona: Curial, 1991-95, 9 vols.

Gaullier-Bougassas, Catherine, 2012: L'Histoire ancienne jusqu'à César ou Histoires pour Roger, châtelain de Lille, de Wauchier de Denain. L'histoire de la Macédoine et d'Alexandre le Grand, Turnhout: Brepols.

Cabré, Miriam, Sadurní Martí \& Marina NAVÀs, 2009: «Geografia i història de la poesia occitanocatalana del segle XIV»), Translatar i transferir. La transmissió dels textos i el saber (12001500), ed. A. Alberni, L. Badia, L. Cabré, Santa Coloma de Queralt: Obrador Edèndum-Univ. Rovira i Virgili, 349-76.

Cabré, Miriam \& Sadurní Martí, 2010: «Le chansonnier Sg au carrefour occitano-catalan», Romania, 128, 92-134.

CARY, G., 1956: The Medieval Alexander, ed. D. J. A. Ross, Cambridge UP.

Cifuentes i Comamala, Lluís, 2006: La ciència en català a l'Edat Mitjana i el Renaixement, Barcelona-Palma, Univ. de Barcelona-Univ. de les Illes Balears.
CINGOLANI, Stefano M., 1990-1991: «Nos en leyr tales libros trobemos plazer e recreation. L'estudi sobre la difusió de la literatura d'entreteniment a Catalunya els segles XIV i XV 》, Llengua \& Literatura, 4, 39-127.

CINGOlani, Stefano M., 2006a: «Miti e archetipi. Mito e storia caballeresca in Catalogna (1040 ca.-1328)», Mito e storia nella tradizione cavalleresca, Spoleto: Centro Italiano di Studi sull'Alto Medioevo, 139-211.

Cingolani, Stefano M., 2006b: Historiografia, propaganda i comunicació al segle XIII: Bernat Desclot i les dues redaccions de la seva Crònica, Barcelona: IEC.

Cingolani, Stefano M. (ed.), 2010: Bernat Desclot. Llibre del rei En Pere, Barcelona: Barcino.

CostANs, Léopold, 1904-12: Le Roman de Troie par Benoit de Sainte-Maure, publié d'après tous les manuscrits connus, París: SATF.

Derbes, Anne \& Marc SAndona, 2004: «Amazons and Crusaders: the Histoire Universelle in Flanders and the Holy Land», France and the Holy Land: Frankish Culture at the End of the Crusades, ed. D. Weiss i L. Mahoney, Baltimore: Johns Hopkins UP, 187-229.

DTCA, Diccionari de Textos Catalans Antics $<$ www.ub.edu/diccionari-dtca>

Eley, Penny, 1992: «The 'Saragossa Fragment' of the Roman de Troie»», Studi francesi, 107, 277-84.

Ferrer i Mallol, M. Teresa (ed.), 2003: Els Catalans a la Mediterrania oriental a l'edat mitjana. Jornades científiques IEC, Barcelona: IEC.

FEW $=$ WARTBURG, Walter von, Französisches Etymologisches Wörterbuch, Bonn-Leipzig, 1922 i seg:; Basilea, 1945 i seg.
FoLDA, Jaroslav, 1976: Crusaders Manuscripts Illumination at SaintJean d'Acre, 1275-1291, Nova Jersey: Princeton UP.

FoldA, Jaroslav, 2005: Crusader Art in the Holy Land: From the Third Crusade to the Fall of Acre, 1187-1291, Cambridge UP.

GamBINO, Francesca, 2003: Canzoni anonime di trovatori e «trobairitz», Alessandria: Edizioni dell'Orso.

JosuIN, Mary Coker (ed.), 1986: The Heard Word: A Moralized History. The Genesis Section of the Histoire ancienne in a Text from Saint-Jean d'Acre, Lafayette: Mississipi UP.

Jung, Marc-René, 1996: La Légende de Troie en France au Moyen Âge: analyse des versions françaises et bibliographie raisonnée des manuscrits, BasileaTübingen: Francke.

HiLKA, Alfons, 1920: Der Altfranzösische Prosa-Alexanderroman, Halle: Niemeyer.

LagomarsinI, Claudio, 2012: «ll Roman de Cardenois e la tradizione manoscritta di Guillaume de Machaut», Romania, 130, 109-33.

Meyer, Paul, 1886: Alexandre le Grand dans la littérature française du Moyen Âge, París: Vieweg, 2 vols.

MinervinI, Laura (ed.), 2000: Cronaca del Templare di Tiro (1243-1314). La caduta degli Stati Crociati nel racconto di un testimone oculare, Nàpols: Liguori.

MinervinI, Laura, 2010: «Le Français dans l'Orient Latin (XIII'-XIV' siècles). Éléments pour la caractérisation d'une scripta du Levant»», Revue de linguistique romane, 74, 119-98.

MonfrIN, Jacques, 1982: «La Place du Secret des secrets dans la littérature française médiévale», Pseudo- 
Aristotle, «The Secret of Secrets»): Sources and Influences, ed. Charles B. Schmitt i W. F. Ryan, Londres: The Warburg Institute, 73-113.

Nobel, Pierre, 2003: «Écrire dans le Royaume franc: la scripta de deux manuscrits copiés à Acre au XIII ${ }^{\mathrm{e}}$ siècle», Variations linguistiques. Koinè dialectes, fr. régionaux, ed. P. Nobel, Besançon: Presses Universitaires de Franche-Comté, 33-52.

Nobel, Pierre, 2006: La Bible D'Acre: Genèse et Exode. Édition Critique d'après les manuscrits Bnf Nouv. Acq. Fr. 1404 et Arsenal 5211, Besançon: Presses Universitaires de Franche-Comté.

Nobel, Pierre, 2013: « L'Exode de la Bible d'Acre transcrit dans un manuscrit de l'Histoire ancienne jusqu'à César», Philologia ancilla litteraturae. Mélanges de philologie et littérature françaises du Moyen Âge offerts au Professeur Gilles Eckard, ed. A. Corbellari, Y. Greub i M. Uhlig, Ginebra: Droz, 195-208.

Oltrogge, Doris, 1989: Die Illustrationszyklen zur «Histoire ancienne jusqu'à César» (1250-1400) Frankfurt: Lang.

Pignatelli, Cinzia \& Dominique Gerner (ed.), 2006: Les Traductions françaises des «Otia imperialia». De Gervais de Tilbury par Jean d'Antioche et Jean de Vignay. Edition de la troisième partie, Ginebra: Droz.

Roux, Brigitte, 2009: Mondes en miniatures. L'iconographie du «Livre du Trésor» de Brunetto Latini, Ginebra: Droz.

RuBió I LLuCH, Antoni, 1947: Diplomatari de l'orient català (1301-1409),

Barcelona, IEC [ibid. 2001, ed. M. T. Ferrer i Mallol].

SCHULZE-BuSACKER, Elisabeth, 2009: «Philippe de Novare, Les Quatre âges de l'homme», Romania, 127, $104-46$.

SÖDERHJELM, Werner, 1917: «Notice et extraits du ms. français 51 de la Bibliothèque Royale de Stockholm»,
Mémoires de la Société Néo-

Philologique de Helsingfors, 6, 305-33.

SW $=$ LEVY, Emil, Provenzalisches Supplement-Wörterbuch, Leipzig, 1894-24, 8 vols.

$T L=$ TOBLER, Adolf i Erhard LOMMATZSCH, Altfranzösisches Wörterbuch, Berlín-Wiesbaden, 1915-2002.

Ventura, Simone, 2006: Intavulare Tavole di canzonieri romanzi. Tables de chansonniers romans, I. Canzonieri provenzali, 10. Barcelona, Biblioteca de Catalunya, Sg (146), Mòdena: Mucchi.

VISSER-VAN-Terwisga, Marjike de, 199599: Histoire ancienne jusqu'à César. Orleans: Paradigme, 2 vols.

WitTlin, Curt, 1971-89: Brunetto Latini, Llibre del Tresor, Barcelona: Barcino, 4 vols. (ENC 102, 111, 122, 125).

ZAMUNER, Ilaria, 2005a: «La tradizione romanza del Secretum secretorum pseudo-aristotelico»», Studi medievali, 46.1, 31-116.

ZAMUNER, Ilaria, 2005b: «ll volgarizzamento catalano Ctz del Secretum secretorum ps.-aristotelico e il codice 1474 della Biblioteca Nacional di Madrid», VIII Convegno dell'AlSC < http://www.filmod.unina. it/aisc/comunicazioni/Zamuner.pdf>

ZINELLI, Fabio, 2007: «Sur les traces de l'atelier des chansonniers provençaux $\mathbb{K}$ : le manuscrit de Vérone, Biblioteca Capitolare, 508 et la tradition méditerranéenne du Livres dou Tresor»», Medioevo Romanzo, 31, 7-69.

ZINELLI, Fabio, 2009-10: «Rapport», École pratique des hautes études, Section des sciences historiques et philologiques, Livret-annuaire, 142 <http://ashp.revues.org/1161>

ZINELLI, Fabio, 2012: «'je qui li livre escrive de letre en vulgal': scrivere il francese a Napoli in età angioina »
Boccaccio angioino. Verso il Centenario, ed. G. Alfano, M.-T. D'Urso i A. Perriccioli Saggese, Berna: Peter Lang, 149-73.

ZINELLI, Fabio, 2012a: «ll Roman de Cardenois, Guillaume de Machaut e Oton de Grandson tra Francia del sud e Catalogna», Romania, 130, 294-354.

ZUFFEREY, François, 1987: Recherches linguistiques sur les chansonniers provençaux, Ginebra: Droz. 